\title{
An insight to metal organic framework derived N-doped graphene towards oxidative degradation of persistent contaminants: Formation mechanism and generation of singlet oxygen from peroxymonosulfate
}

Ping Liang ${ }^{1}$, Chi Zhang ${ }^{1}$, Xiaoguang Duan ${ }^{1}$, Hongqi Sun ${ }^{2 *}$, Shaomin Liu ${ }^{1}$, Moses O. Tade ${ }^{1}$, and Shaobin Wang ${ }^{1 *}$

${ }^{1}$ Department of Chemical Engineering, Curtin University, GPO Box U1987, Perth, Western Australia 6845, Australia

${ }^{2}$ School of Engineering, Edith Cowan University, 270 Joondalup Drive, Joondalup, Western Australia 6027, Australia

Corresponding authors.

*Email: shaobin.wang@ curtin.edu.au (S. Wang); h.sun@ecu.edu.au (H. Sun) 


\begin{abstract}
Synthesis of carbonaceous materials from metal organic framework (MIL-100), organic linker and $\mathrm{N}$-precursor was comprehensively investigated and their structures were characterized. It was found that simple pyrolysis of mixed MIL-100 (Fe)/dicyandiamide (DCDA) could produce nitrogen doped graphene (N-graphene). The $\mathrm{N}$-graphene showed excellent performances in peroxymonosulfate (PMS) activation, superior to the counterparts of graphene, iron (II, III) oxide, manganese (IV) oxide and cobalt (II, III) oxide. With PMS activation, N-graphene exhibited efficient catalytic degradation of various organic pollutants such as phenol, 2,4,6-tricholophenol (TCP), sulfachloropyridazine (SCP) and p-hydroxybenzoic acid (PHBA). The electron paramagnetic resonance (EPR) and radical quenching tests were employed to investigate the PMS activation and organic degradation processes. It was found that singlet oxygen $\left({ }^{1} \mathrm{O}_{2}\right)$ was mainly produced during the activation of PMS by Ngraphene and contributed to the catalytic oxidation instead of sulfate and/or hydroxyl radicals. These findings provided new insights into PMS activation by metal-free carboncatalysis.
\end{abstract}

Keywords: metal-free catalysis; MOF; MIL-100; N-doped graphene; singlet oxygen 


\section{Introduction}

The worldwide water shortage and pollution has been intriguing the development of remediation technologies for water treatment. Peroxymonosulfate (PMS), persulfate (PS) and hydrogen peroxide $\left(\mathrm{H}_{2} \mathrm{O}_{2}\right)$ are generally used as oxidants for degradation of aqueous pollutants by advanced oxidation processes (AOPs) ${ }^{1-3}$. In the processes, complete degradation of organic pollutants can be achieved by generating sulfate and/or hydroxyl radicals ${ }^{4,5}$. However, as acidic condition is usually required, metal-based catalysts tend to cause secondary contamination due to hazardous metal leaching ${ }^{6}$. Hence, metal-free materials are highly demanded as the catalysts for removal of organic pollutants.

Graphene is considered as a promising green catalyst owing to its high surface area, chemical stability and impressive electrical conductivity ${ }^{7}$. Sun et al. ${ }^{3}$ firstly reported that reduced graphene oxide (rGO) could activate PMS for degradation of organic pollutants. It has been further proven that the electronic and chemical performances of graphene are sensitive to heteroatom (nitrogen, phosphorus, sulfur or boron) doping which would induce more active sites on the graphene surfaces ${ }^{8-11}$. Nitrogen doping has been widely demonstrated to be effective due to the resemblance of carbon and nitrogen atomic sizes and strong covalence between them ${ }^{12}$. N-graphene could be feasibly synthesized through routes such as chemical vapor deposition $(\mathrm{CVD})^{13}$, arc-discharge ${ }^{14}$, segregation growth ${ }^{15}$ and post-synthesis treatment ${ }^{16}$. However, the above methods are time-consuming and require critical synthesis conditions, thus a novel and facile route as an alternative is demanded ${ }^{11,17}$.

Metal-organic frameworks (MOFs), as promising crystalline porous materials, have been explored for many applications such as gas separation, catalysis and removal of pollutants by adsorption ${ }^{18-21}$. Given the good configuration of metal clusters and organic ligands as well as tuneable porous structures, MOFs were employed as self-sacrificial templates or precursors to fabricate carbon or hybrid composites via pyrolysis ${ }^{22-24}$. Graphene nanostructures were also fabricated via the graphitization processes of heteroatom polymers in the presence of iron or cobalt species ${ }^{25-27}$. Li et al. ${ }^{17,28}$ synthesized the graphene/graphene tube nanocomposites templated by a cage-containing 
cobalt (II) MOF and the bamboo-like nitrogen-doped graphene tubes using MIL-100 (Fe) and dicyandiamide (DCDA) as the precursors, showing excellent performances in oxygen reduction reaction (ORR). Mao et $a l .{ }^{29}$ fabricated highly graphitized, nitrogen-doped carbon spheres with capsulation of iron nanoparticles using MIL-100 (Fe) and DCDA as the precursors for ORR. Lv et $a l .{ }^{30}$ constructed porous Co/carbon composites by thermal decomposition of ZIF-67 under an inert gas, obtaining splendid electromagnetic wave absorption properties. However, few attempts were made on the understanding of carbon formation from different precursors of MOFs and the application in activation of oxidants for removal of organic pollutants in water on MOF-templated Ngraphene.

Herein, we synthesized N-graphene templated by MIL-100 with DCDA and other carbons from the precursors towards MIL-100. The catalytic performances were evaluated by degradation of various organic pollutants in aqueous solutions. Electron paramagnetic resonance (EPR) and radical quenching tests were carried out to investigate the mechanism of PMS activation on N-graphene. In our previous discussions ${ }^{31,32}$, nonradical reaction was generated during PMS activation on N-doped single-walled carbon nanotubes, reduced graphene oxide and annealed nanodiamond. However, the nonradical species was not specified. In this study, singlet oxygen $\left({ }^{1} \mathrm{O}_{2}\right)$ was identified for the first time to contribute to the activation of PMS on $\mathrm{N}$-graphene instead of hydroxyl $(\bullet \mathrm{OH})$ and sulfate $\left(\mathrm{SO}_{4}{ }^{\circ}\right)$ radicals, which provides new insight into the PMS activation mechanism towards organic oxidation.

\section{Experimental}

\subsection{Materials and chemicals}

Iron(III) nitrate nonahydrate $\left(\mathrm{Fe}\left(\mathrm{NO}_{3}\right)_{3} \bullet 9 \mathrm{H}_{2} \mathrm{O}, 100 \%\right)$, benzene trimesic acid (BTC, 95\%), DCDA (99.9\%), sulfuric acid $\left(\mathrm{H}_{2} \mathrm{SO}_{4}, 98 \%\right)$, potassium peroxymonosulfate (Oxone® or PMS), phenol (99.0\%), sulfachloropyridazine (SCP, 99.9\%), p-hydroxybenzoic acid (PHBA, 99\%), 2,4,6trichlorophenol (TCP, 99.9\%), manganese (IV) oxide $\left(\mathrm{MnO}_{2}, 100 \%\right)$, iron (II, III) oxide $\left(\mathrm{Fe}_{3} \mathrm{O}_{4}\right.$, 
100\%), 2,2,6,6-tetramethyl-4-piperidinol (TMP, 99\%), 5,5-dimethyl-1-pyrroline N-oxide (DMPO, 99.0\%), tert-butanol (TBA, 99.5\%), ethanol (99.5\%), methanol and acetonitrile of HPLC grade were purchased from Sigma-Aldrich. Sodium azide $\left(\mathrm{NaN}_{3}, 99.5 \%\right)$ was purchased from Rowe Scientific.

\subsection{Preparation of samples}

MIL-100 (Fe) was synthesized via a fluorine-free route by the hydrothermal reactions as reported elsewhere ${ }^{33}$. As shown in Scheme S1, $4 \mathrm{~g}$ of DCDA and $0.25 \mathrm{~g}$ of MIL-100 were mixed in ethanol and kept stirring at $80{ }^{\circ} \mathrm{C}$ for $8 \mathrm{~h}$. The solvent was evaporated at $60{ }^{\circ} \mathrm{C}$ and then the solid was heated at $800{ }^{\circ} \mathrm{C}$ for $2 \mathrm{~h}$ in $\mathrm{N}_{2}$. The resulting sample was labelled as $\mathrm{N}-\mathrm{C}-\mathrm{Fe}$. The $\mathrm{N}-\mathrm{C}-\mathrm{Fe}$ was then washed by $0.5 \mathrm{M} \mathrm{H}_{2} \mathrm{SO}_{4}$ at $80{ }^{\circ} \mathrm{C}$ for $24 \mathrm{~h}$ to remove the unstable iron species, designated as N-G. MOF-C was prepared by the similar procedure without DCDA. BTC-C and C-N were obtained by pyrolysis of BTC and BTC/DCDA, respectively, under the same condition as N-C-Fe. The synthesis conditions of the samples in this study are shown in Table 1. Cobalt (II, III) oxide $\left(\mathrm{Co}_{3} \mathrm{O}_{4}\right)$ was obtained from a previous report ${ }^{34}$.

Table 1. The synthesis conditions of different samples.

\begin{tabular}{cccc}
\hline Sample name & Precursors & Pyrolysis condition & Acid washing \\
\hline BTC-C & BTC & $800^{\circ} \mathrm{C}$ for $2 \mathrm{~h}$ under $\mathrm{N}_{2}$ & $\mathrm{NO}$ \\
C-N & BTC+DCDA & $800^{\circ} \mathrm{C}$ for $2 \mathrm{~h}$ under $\mathrm{N}_{2}$ & NO \\
MOF-C & MIL-100 & $800^{\circ} \mathrm{C}$ for $2 \mathrm{~h}$ under $\mathrm{N}_{2}$ & YES \\
N-C-Fe & MIL-100+DCDA & $800^{\circ} \mathrm{C}$ for $2 \mathrm{~h}$ under $\mathrm{N}_{2}$ & NO \\
N-G & MIL-100+DCDA & $800^{\circ} \mathrm{C}$ for $2 \mathrm{~h}$ under $\mathrm{N}_{2}$ & YES \\
\hline
\end{tabular}

\subsection{Characterization of the samples}

Powder X-ray diffraction (XRD) patterns were obtained on a Bruker D8-Advance X-ray diffractometer with $\mathrm{Cu} \mathrm{K} \alpha$ radiation $(\lambda=1.5418 \AA ̊)$. Field emission scanning electron microscopy 
(FE-SEM, Zeiss Neon 40 EsB) and transmission electron microscopy (TEM, JEOL 2100) were employed to investigate the morphologies of the samples. The composition and chemical states were studied on X-ray photoelectron spectroscopy (XPS) using a Kratos AXIS Ultra DLD system with AlK $\alpha$ X-ray. Thermogravimetric-differential thermal analysis (TG-DTA) was carried on a TGA/DSC1 thermogravimetric analyzer from Mettler-Toledo Instrument in the inert atmosphere to acquire the mass loss of MIL-100. $\mathrm{N}_{2}$ adsorption/desorption isotherms were acquired at $-196{ }^{\circ} \mathrm{C}$ on a Tristar 3020 to obtain the specific surface area (SSA) and pore size distributions according to the BrunauerEmmett-Teller (BET) equation and the Barrett-Joyner-Halenda (BJH) method, respectively.

\subsection{Catalytic performances in degradation of organics}

The experiments were conducted in a thermostatic water bath with the catalysts $(0.1 \mathrm{~g} / \mathrm{L})$ and PMS (1 g/L) and target pollutants (e.g., phenol (50 ppm), SCP (20 ppm), TCP (50 ppm), and PHBA (20 $\mathrm{ppm})$ ) in a glass reactor. At a given interval, $1 \mathrm{~mL}$ of solution was withdrawn by a syringe, filtered by a $0.45 \mu \mathrm{m}$ Millipore film, and injected into a vial which held $0.5 \mathrm{~mL}$ of methanol as a quenching agent. The resulting solution was analyzed on a high performance liquid chromatograph (HPLC, Varian) with a C-18 column. For the stability tests, the samples were collected and washed several times by deionized water after $3 \mathrm{~h}$ reactions, and then dried in air at $60{ }^{\circ} \mathrm{C}$.

\subsection{Mechanistic studies}

The contributors during the degradation of organics by the activation of PMS were detected by electron paramagnetic resonance (EPR). DMPO was selected to be the spin-trapping agent for $\mathrm{SO}_{4}{ }^{-}$ and ${ }^{\circ} \mathrm{OH}$. TMP was used to capture singlet oxygen $\left({ }^{1} \mathrm{O}_{2}\right)$ which would oxidize TMP into 2,2,6,6tetramethyl-4-piperidinol-N-oxyl radical (TMPN). The quantitative results and intensity of TMPN were obtained directly by Spin Fitting from Bruker Xenon Software package. The reactive radicals and nonradical reactions were identified by classical quenching tests. Specifically, ethanol and TBA were used as the quenching agents for hydroxyl and sulfate radicals, respectively, while sodium azide would verify the existence of singlet oxygen. 


\section{Results and Discussion}

\subsection{Characterization of the materials}

XRD patterns of the resulting carbonaceous materials are shown in Figure 1a. BTC-C and C-N were identified as amorphous carbons containing a low level of graphitized carbon by XRD ${ }^{35}$. The (002) peak at $26^{\circ}(2 \theta)$ corresponding to graphene could be detected for MOF-C, N-C-Fe and N-G, due to the catalytic role of iron species in the precursor of MIL-100 ${ }^{36}$. The (002) peak shifted from 26.5 to $26.1^{\circ}$ after $\mathrm{N}$ doping, indicating an increased interlayer spacing ${ }^{13}$. Zero-valent iron $(\alpha-\mathrm{Fe})$ at the peak of $44.8^{\circ}$ could not be eliminated by the post-treatment of acid washing for MOF-C, probably due to the capsulation by carbon. The peaks at $31.1,35.6$ and $43.1^{\circ}$ of $\mathrm{N}-\mathrm{C}$-Fe were assigned to $\gamma$ $\mathrm{Fe}_{2} \mathrm{O}_{3}$ which was formed during the collapse of MIL-100 at around $470{ }^{\circ} \mathrm{C}$ (Figure S1, Supporting Information). The peaks at 43.7 and $44.8^{\circ}$ corresponded to $\mathrm{Fe}_{3} \mathrm{C}$ and $\alpha$-Fe, respectively, forming after the annealing at about $600{ }^{\circ} \mathrm{C}$ (Figure S1a). After $\mathrm{H}_{2} \mathrm{SO}_{4}$ digestion, only the peak at $26.1^{\circ}$ presented without peaks assigned to iron species for $\mathrm{N}-\mathrm{G}$, which differed from $\mathrm{MOF}-\mathrm{C}$ as discussed above. The mass ratio of Fe residue in N-G was much less than MOF-C due to the addition of DCDA with MOF for $\mathrm{N}-\mathrm{G}$ production. The no detection of Fe species in $\mathrm{N}-\mathrm{G}$ may be attributed to the fact that the low quantity of the iron species was below the detection limit of XRD analysis.

Raman spectra of MOF-C and N-G in Figure 1b showed the vibration of the edges/defects (D band) at $1354 \mathrm{~cm}^{-1}$ and graphite lattice (G band) at $\sim 1580 \mathrm{~cm}^{-1}$. Specifically, the $\mathrm{G}$ band of $\mathrm{N}-\mathrm{G}$ was broaden and shifted to a higher frequency compared with MOF-C (blue shift, 1581 vs. $1576 \mathrm{~cm}^{-1}$ ). The $\mathrm{I}_{\mathrm{D}} / \mathrm{I}_{\mathrm{G}}$ (the intensity ratio of $\mathrm{D}$ band and $\mathrm{G}$ band) of $\mathrm{N}-\mathrm{G}$ increased to 0.90 from 0.71 for MOF-C, indicating that $\mathrm{N}$ doping increased the defectiveness of graphene. Meanwhile, the smaller $\mathrm{I}_{2 \mathrm{D}} / \mathrm{I}_{\mathrm{G}}$ of $\mathrm{N}-\mathrm{G}$ compared to that of MOF-C $(0.448 v s .1 .86)$ confirmed the conclusion above. 

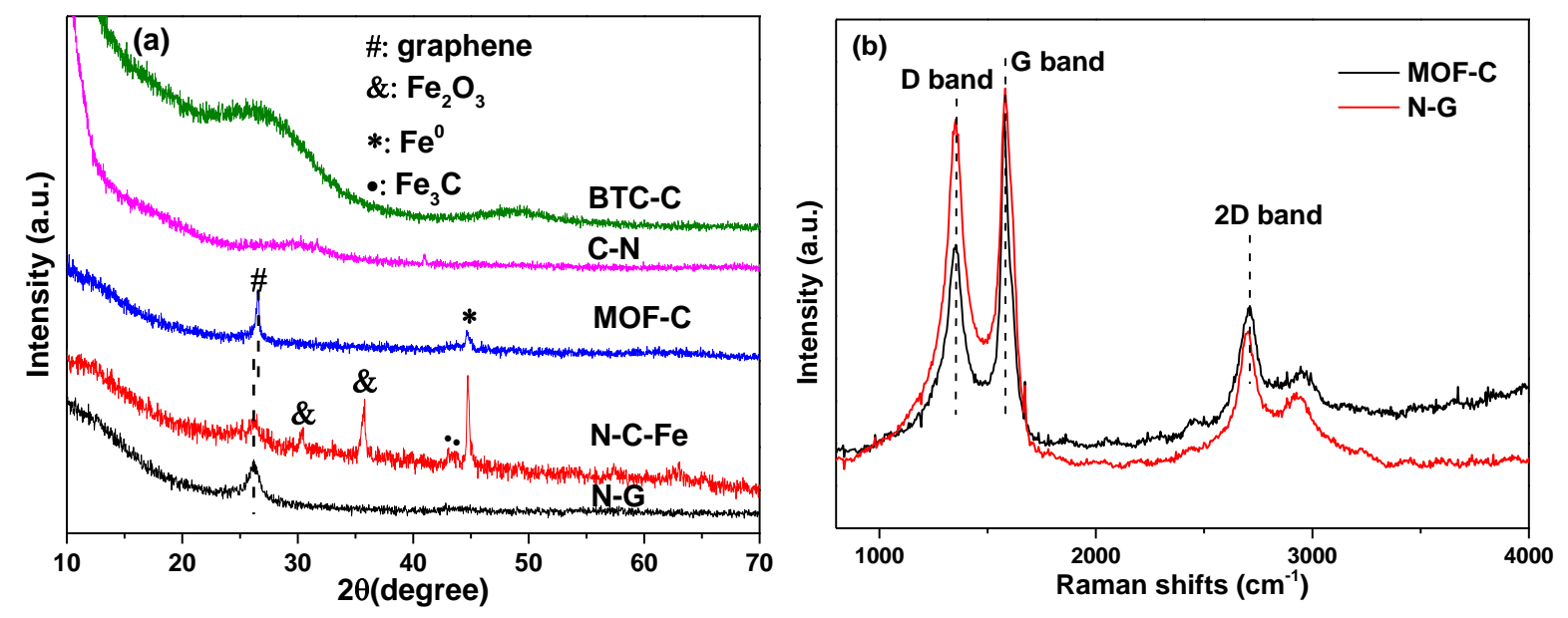

Figure 1. XRD patterns (a) and Raman spectra (b) of catalysts.

The particles of MIL-100 are mainly in polyhedra (Figure S2). After carbonizing MIL-100/DCDA at $800{ }^{\circ} \mathrm{C}, \mathrm{N}-\mathrm{C}-\mathrm{Fe}$ was formed with the collapse of the polyhedral shape of MIL-100, showing ironbearing nanoparticles embedded within carbonaceous materials (Figure 2a). The iron species dispersed uniformly due to the separation of carbon materials (Figure 2b). The HRTEM in Figure 3c showed that iron species were surrounded by onion-like graphitic carbon. The nanoparticles were eliminated by acid digestion for the formation of N-G (Figure 2d). The TEM (Figure 2e) confirmed the removal of iron nanoparticles and a tiny amount of iron particles still remained, which escaped from acid wash. Figure $2 \mathrm{f}$ showed that $\mathrm{N}-\mathrm{G}$ was hollow onion-like graphitic carbon. In addition, the monolith of BTC-C was amorphous carbon while some sheet-like ordered carbon appeared on C-N (Figure S2b-c, e-f). Similar to N-G, MOF-C also exhibited hollow onion-like shells with minimal iron particles left (Figure S2d, g).
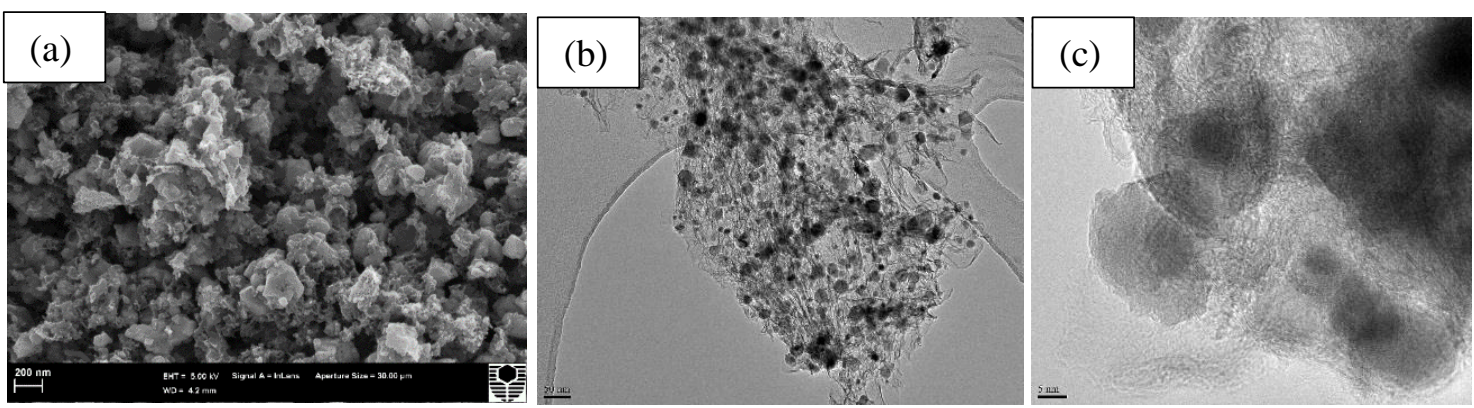

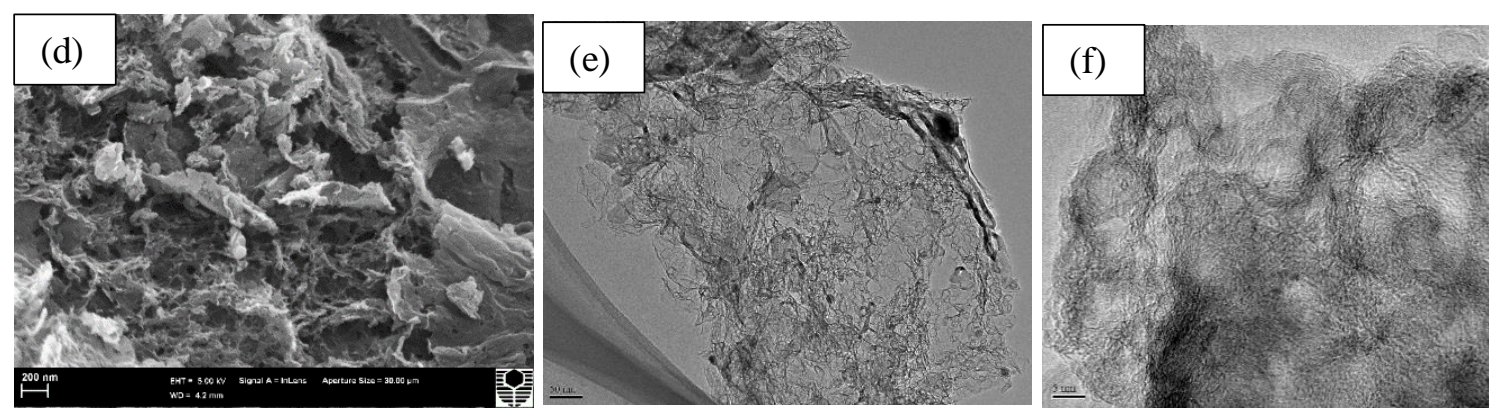

Figure 2. SEM images (a,d), TEM images $(b, e)$ and HRTEM images $(c, f)$ of $N-C-F e(a-c)$ and NG(d-f).

The formation mechanisms of different carbonaceous materials from varying precursors were discussed. BTC molecules were linked by hydrogen bond $\mathrm{C}-\mathrm{O} \cdots \mathrm{H}$ (Scheme S2a). At low pyrolysis temperature, water was driven off accompanied by the condensation of BTC. Upon further heating, carbon-carbon bonds were formed with the loss of oxygen via $\mathrm{CO}_{\mathrm{x}}$. With the increase of temperature, the six carbon phenyl rings broke and formed layered carbon network which was confirmed to be amorphous carbon. The formation mechanism of amorphous carbon in $\mathrm{C}-\mathrm{N}$ was similar to that of BTC-C. In addition, DCDA would be decomposed to layered graphitic carbon nitride which confined the as-formed carbon intermediates to the interlayer gaps ${ }^{37}$. When the pyrolysis temperature went above $750{ }^{\circ} \mathrm{C}$, carbon nitride was subjected to complete thermolysis and sheet-like ordered carbon formed (Scheme S2b). Therefore, ordered carbon could be formed in $\mathrm{C}-\mathrm{N}$ besides the amorphous carbon. MIL-100 and DCDA were interconnected by hydrogen bonds $\mathrm{N}-\mathrm{H} \cdots \mathrm{O}$ and $\mathrm{O}-\mathrm{H} \cdots \mathrm{N}$ (Scheme 1). Upon pyrolysis, the framework of MOF collapsed with the condensation of polymers, releasing water vapor, $\mathrm{CO}_{\mathrm{x}}, \mathrm{NH}_{\mathrm{x}}$ and $\mathrm{NO}_{\mathrm{x}}$. The iron species were firstly decomposed to metallic oxides and then reduced to iron metals by the carbon surrounding them ${ }^{38}$. Liquid mobile iron-carbon particles could form at relatively low temperatures $\left(600-670{ }^{\circ} \mathrm{C}\right)$ as reported by Krivoruchko et al. ${ }^{39}$ Here, the carbon and nitrogen species dissolved into iron particles at high pyrolysis temperatures and precipitated out as curved graphitic carbon when supersaturation was reached, named in dissolutionprecipitation dynamic equilibrium ${ }^{40}$. The released graphitic layers were rearranged into closed shells following the energy minimization principle and the van der Waals interactions between the shells 
stabilized the system ${ }^{41}, 42$. Conclusively, after the procedure of condensation, dissolution, precipitation and rearrangement, N-C-Fe exhibited metal-enclosed shell structure and N-G showed hollow onion-like shells after metal removal by acid wash. The formation mechanism of MOF-C was similar to N-G, without the addition of DCDA (Scheme S2c).

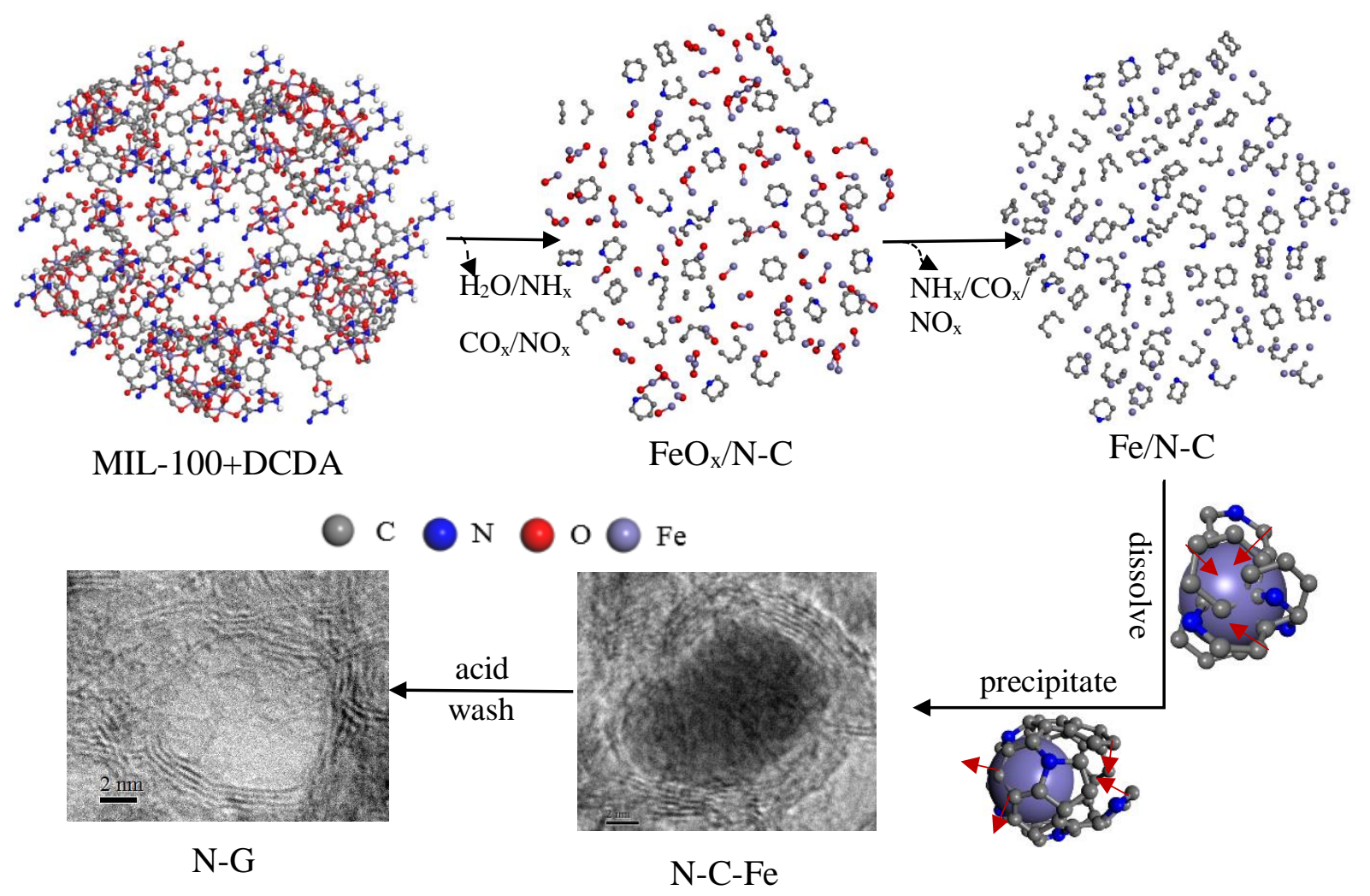

Scheme 1. The formation mechanism of N-C-Fe and N-G.

The compositions and chemical states of N-C-Fe and N-G were analyzed by XPS. As shown in Figure 3a, the oxygen content of N-C-Fe decreased from 4.10 at. $\%$ to 2.99 at. $\%$ after post-acid treatment, due to the loss of $\mathrm{Fe}_{2} \mathrm{O}_{3}$. N-C-Fe and N-G contained much lower oxygen levels than Ndoped reduced graphene oxide (N-rGO, 11.53 at.\%) and rGO (14.44 at.\%) ${ }^{34}$, therefore, the oxygen groups in the samples contributed little to the catalytic oxidation ${ }^{31}$. N-C-Fe and N-G contained a similar N content, 2.91 at.\% and 2.31 at.\%, respectively. As shown in Figure 3b, three high-resolution $\mathrm{N}$ peaks of N-C-Fe and $\mathrm{N}-\mathrm{G}$ were observed at 398.6, 401.1 and $403.9 \mathrm{eV}$, corresponding to pyridinic $\mathrm{N}$, graphitic $\mathrm{N}$ and nitrogen oxide, respectively ${ }^{17}, 43$. The results suggested that nitrogen was successfully doped into graphene. As previously reported, the existence of Fe facilitated the formation 
of quaternary $\mathrm{N}$ in high temperature pyrolysis of carbon/nitrogen precursors ${ }^{36,44}$. Both N-C-Fe and $\mathrm{N}-\mathrm{G}$ showed a higher content of graphitic $\mathrm{N}$ (one specific type of quaternary $\mathrm{N}$ within graphene plane) than that of pyridinic $\mathrm{N}$, suggesting that nitrogen atoms preferred to be doped into the basal plane instead of the edges of graphene sheets. The de-convoluted C1s XPS spectra of N-C-Fe and N-G (Figure S3) centred at 284.6, 285.8, 286.7 and $290.1 \mathrm{eV}$, assigning to $\mathrm{sp}^{2}-\mathrm{C}, \mathrm{C}=\mathrm{N} / \mathrm{C}-\mathrm{O}, \mathrm{C}-\mathrm{N} / \mathrm{C}=\mathrm{O}$ and $\pi-\pi^{*}$ shake-up satellite, respectively ${ }^{7,45}$.
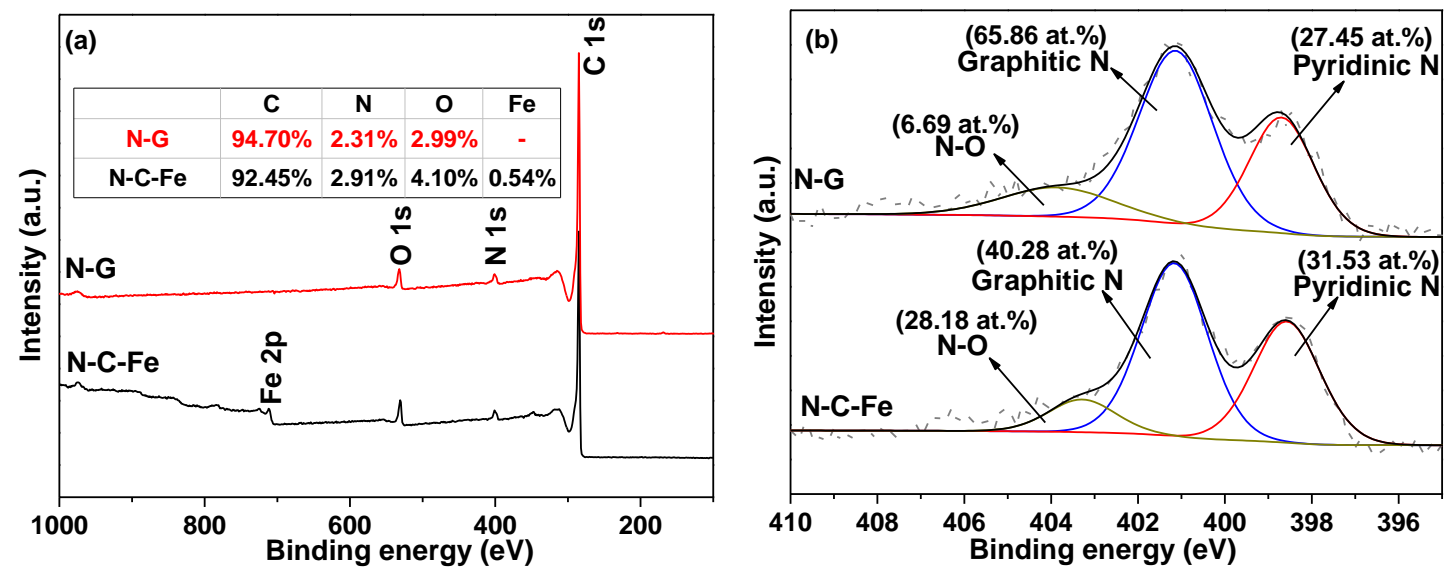

Figure 3. (a) XPS survey and (b) N 1s spectra of N-C-Fe and N-G.

The SSA and pore size distribution of the samples were investigated through $\mathrm{N}_{2}$ adsorption/desorption isotherms. The curves shown in Figure 4a agreed with a type IV isotherm and H3 hysteresis loop. The SSA and pore volume of N-G $\left(351.2 \mathrm{~m}^{2} / \mathrm{g}\right.$ and $0.597 \mathrm{~cm}^{3} / \mathrm{g}$, respectively) were much higher than those of C-N $\left(219.2 \mathrm{~m}^{2} / \mathrm{g}\right.$ and $\left.0.484 \mathrm{~cm}^{3} / \mathrm{g}\right)$, MOF-C $\left(206.1 \mathrm{~m}^{2} / \mathrm{g}\right.$ and 0.383 $\left.\mathrm{cm}^{3} / \mathrm{g}\right)$ and N-C-Fe $\left(212.2 \mathrm{~m}^{2} / \mathrm{g}\right.$ and $0.351 \mathrm{~cm}^{3} / \mathrm{g}$ ) (Figure $\left.4 \mathrm{~b}\right) . \mathrm{C}-\mathrm{N}$ presented slightly higher SSA and pore volume than MOF-C and N-C-Fe due to the presence of iron in the latter two samples. The addition of DCDA, the framework of MIL-100 as the template and the post-acid treatment for removal of unstable iron species induced more porous structures and higher surface areas. The pore size of the materials above mainly ranged from 0 to $5 \mathrm{~nm}$ (Figure $\mathrm{S} 4$ ). 

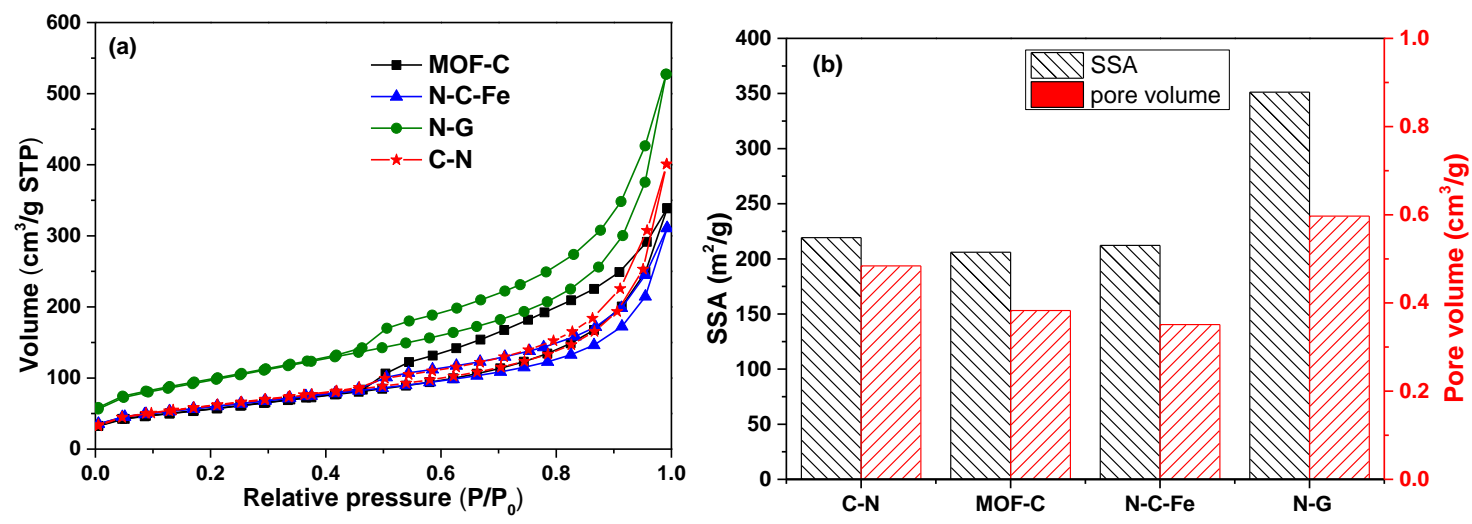

Figure 4. $\mathrm{N}_{2}$ sorption isotherms (a) and SSA/pore volumes (b) of the catalysts.

\subsection{Catalytic oxidation of organic pollutants}

The catalytic degradation of phenol solutions on various materials is shown in Figure 5a. PMS alone without a catalyst exhibited negligible oxidation of phenol. The catalytic oxidation can deliver more effective removal of organics. For BTC-C, less than $10 \%$ phenol was degraded within 180 min, while $80 \%$ phenol removal was achieved on $\mathrm{C}-\mathrm{N}$. It was suggested that $\mathrm{N}$ doping could significantly improve the catalytic effect by boosting the electron transfer ${ }^{34}$. About $90 \%$ phenol was decomposed within 180 min on MOF-C, which was superior to C-N, even though the C-N (doped by N 7.43 at.\%, Figure S5a) had a higher SSA and pore volume than MOF-C. This is because free electron flowing of graphene on MOF-C facilitated more effective catalytic oxidation, compared with amorphous carbon of C-N ${ }^{3}$. Almost $98 \%$ phenol was removed on N-C-Fe in $180 \mathrm{~min}$. The XRD results in Figure S6 showed that the peaks assigned to $\mathrm{Fe}_{2} \mathrm{O}_{3}$ became weaker after the $1^{\text {st }}$ run, indicating that $\mathrm{Fe}_{2} \mathrm{O}_{3}$ worked during PMS activation for $\mathrm{N}-\mathrm{C}-\mathrm{Fe}$. $\mathrm{N}-\mathrm{G}$ presented the greatest catalysis for phenol degradation, with 100\% phenol removal within 30 min. Meanwhile, N-G showed minor adsorption of phenol. Thereby, the decomposition of phenol on N-G was mainly attributed to catalytic oxidation. It was noteworthy that C-N showed a higher content and the similar chemical states of N (Figure S5) compared with N-G, while the catalytic efficiency was inferior to that of N-G. It could be explained by both the higher SSA/pore volume and graphene structure of N-G. It could be concluded that the fascinating metal-free catalysis on N-G was contributed by high SSA/pore volume, N doping and 
graphene structure. The reusability of N-G in catalytic degradation of phenol is shown in Figure S7. About $100 \%$ and $61 \%$ phenol removals were achieved in 120 and 180 min for the second and third runs, respectively, indicating that $\mathrm{N}-\mathrm{G}$ showed a much better stability than $\mathrm{rGO}^{3}$ and $\mathrm{N}-\mathrm{rGO}^{34}$. The deactivation of N-G catalysts was attributed to the change of surface chemistry and structure covered by produced intermediates ${ }^{46}$. N-G showed weaker defectiveness $\left(\mathrm{I}_{\mathrm{D}} / \mathrm{I}_{\mathrm{G}}=0.9\right)$, compared with $\mathrm{rGO}$ $\left(\mathrm{I}_{\mathrm{D}} / \mathrm{I}_{\mathrm{G}}=1.48\right)$ and $\mathrm{N}-\mathrm{rGO}\left(\mathrm{I}_{\mathrm{D}} / \mathrm{I}_{\mathrm{G}}=1.34\right)$. As a result, the surface chemistry of $\mathrm{N}-\mathrm{G}$ was more stable than the highly defective rGO and N-rGO, inducing an excellent stability in catalytic performances.

The effect of reaction temperature on catalytic oxidation is shown in Figure 5b. The temperature exhibited a slight influence on phenol degradation. According to the Arrhenius equation, the activation energy on $\mathrm{N}-\mathrm{G}$ was calculated to be $15.8 \mathrm{~kJ} / \mathrm{mol}$ (the initial concentration of phenol 50 ppm, catalyst $100 \mathrm{mg} / \mathrm{L}$ ), which was lower than the value of materials previously reported such as graphene $(84.0 \mathrm{~kJ} / \mathrm{mol}), \mathrm{N}-\mathrm{rGO}(31.6 \mathrm{~kJ} / \mathrm{mol})$ and $\mathrm{N}$-doped carbon nanotube $(\mathrm{N}-\mathrm{CNT}, 39.2 \mathrm{~kJ} / \mathrm{mol})$ $3,7,47$. The lower activation energy of $\mathrm{N}-\mathrm{G}$ could be attributed to the higher surface area $\left(351.2 \mathrm{~m}^{2} / \mathrm{g}\right)$ than others $\left(<160 \mathrm{~m}^{2} / \mathrm{g}\right)$ as well as $\mathrm{N}$ doping, inducing more active sites participating in the reactions and boosting the electron transfer.

The catalytic oxidation of phenol on N-G was also much better than the generally used metal-based catalysts such as $\mathrm{Fe}_{3} \mathrm{O}_{4}, \mathrm{MnO}_{2}$ and $\mathrm{Co}_{3} \mathrm{O}_{4}$ (Figure 5c). Moreover, N-G also showed excellent degradation efficiencies of some other organic pollutants such as SCP, PHBA and TCP (Figure 5d).
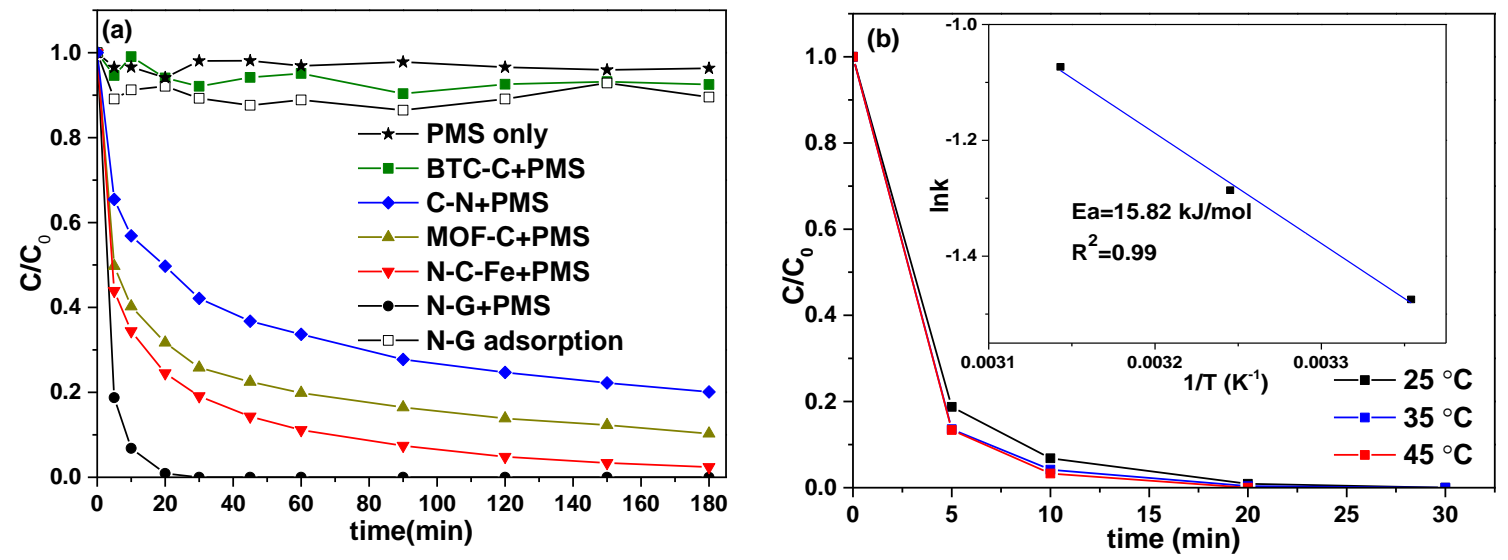

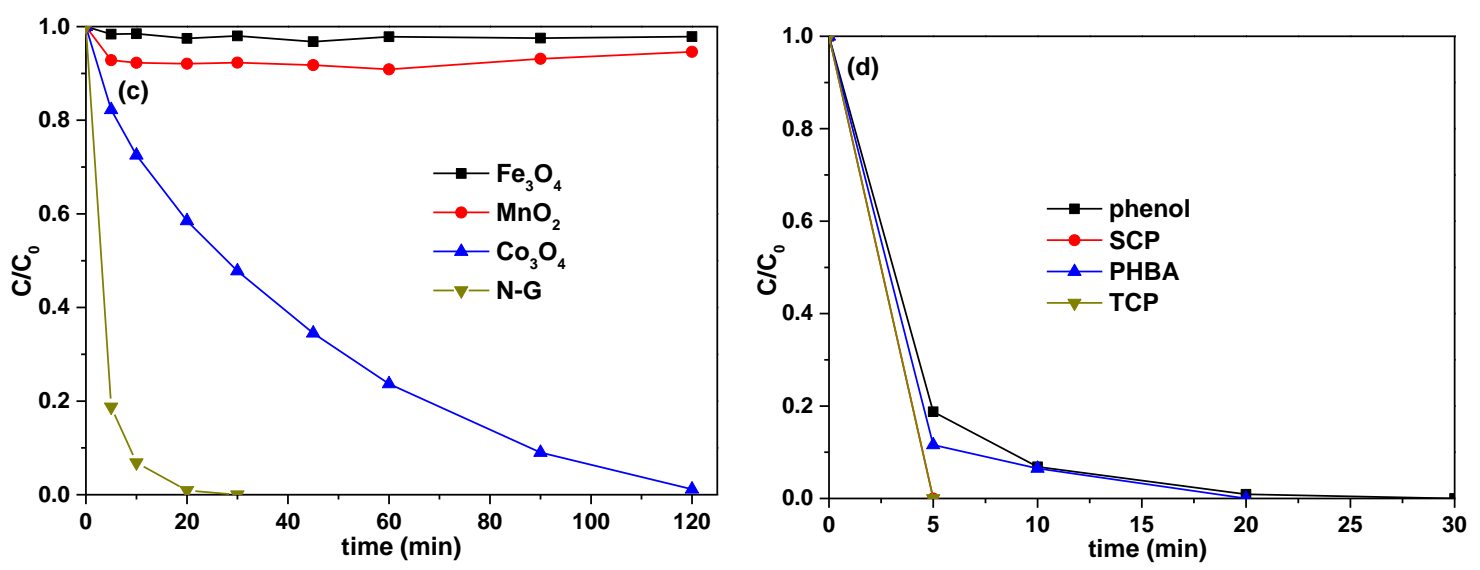

Figure 5. Phenol removal on various catalysts (a); effect of reaction temperature on phenol removal on $\mathrm{N}-\mathrm{G}$ and activation energy (inset) (b); phenol removal on $\mathrm{N}-\mathrm{G}$ and various metal-based catalysts (c); various pollutant removals on $\mathrm{N}-\mathrm{G}$ (d). Reaction conditions: catalyst $100 \mathrm{mg} / \mathrm{L}$, PMS $3.25 \mathrm{mM}$, phenol 50 ppm, SCP 20 ppm, PHBA 20 ppm, TCP 50 ppm, temperature $25{ }^{\circ} \mathrm{C}$ (if not mentioned specifically).

\subsection{Mechanism of the catalytic oxidation}

In the previous studies, hydroxyl and sulfate radicals were found to be produced during PMS activation by metal-based catalysts and $\mathrm{N}-\mathrm{rGO}^{7,48}$. Here, EPR was employed to examine free radicals generated during PMS activation using DMPO as a radical spin trapping agent. As shown in Figure 6a, DMPO-OH and DMPO-SO 4 peaks could be observed on MOF-C, N-C-Fe and N-G, indicating that $\bullet \mathrm{OH}$ and $\mathrm{SO}_{4}{ }^{--}$radicals were generated during PMS activation by the three catalysts. Meanwhile, DMPO-OH peaks were greatly higher than $\mathrm{DMPO}_{-} \mathrm{SO}_{4}$. In this research, the hydroxyl radicals' intensity from N-G catalysis was much lower than that of N-C-Fe. However, N-G exhibited a higher catalytic oxidation than N-C-Fe. Furthermore, Figure 6 b reveals that the intensity of $\bullet \mathrm{OH}$ radicals for $\mathrm{N}-\mathrm{G}$ climbed fastest between 5 and 10 min while the degradation rate of phenol reached the maximum at the initial $5 \mathrm{~min}$. Conclusively, hydroxyl radicals were not the dominating radicals during phenol oxidation via PMS activation on $\mathrm{N}-\mathrm{G}$. 

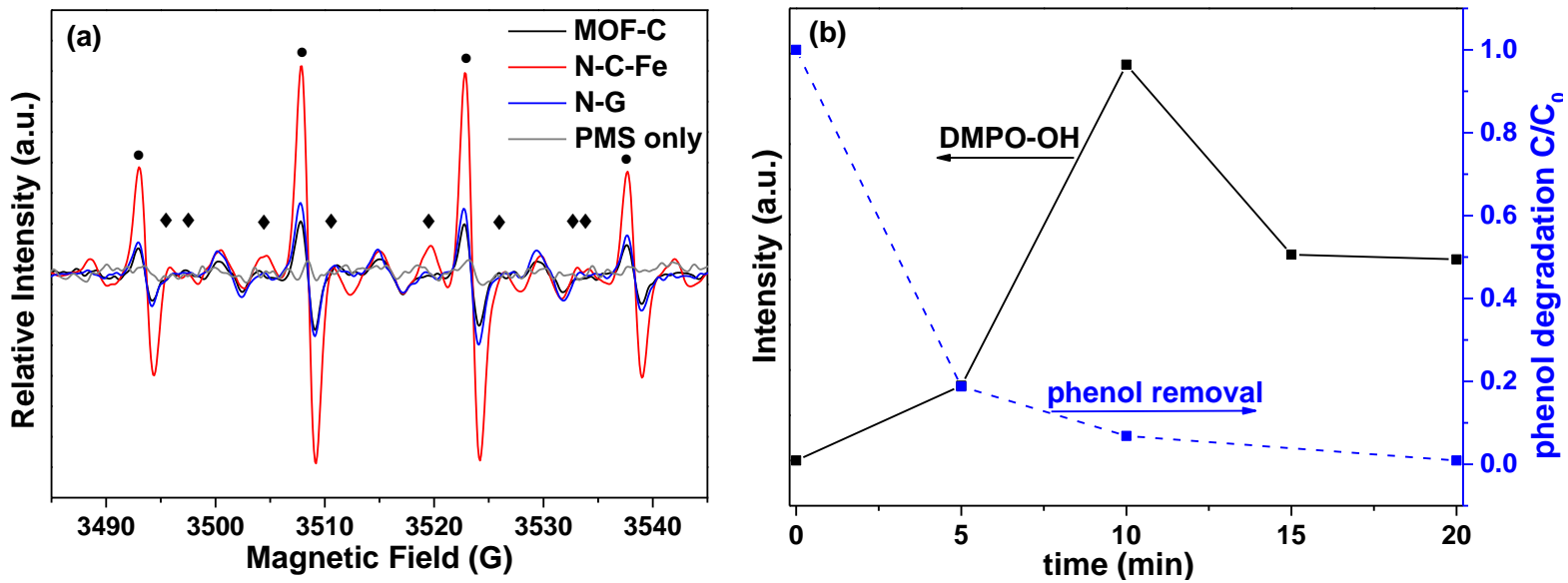

Figure 6. EPR spectra of PMS activation on various catalysts (a) and variation of hydroxyl radicals and phenol removal during PMS activation on N-G (b). (catalyst: $100 \mathrm{mg} / \mathrm{L}$, PMS: $3.25 \mathrm{mM}$, phenol: 50 ppm, temperature: $25^{\circ} \mathrm{C} . \bullet: \mathrm{DMPO}-\mathrm{OH}, \diamond: \mathrm{DMPO}^{\left.-\mathrm{SO}_{4}\right)}$.

It was reported that ${ }^{1} \mathrm{O}_{2}$ can be generated during the self-decomposition of PMS and the rate constant $\kappa$ is about $0.2 \mathrm{M}^{-1} \mathrm{~s}^{-149,50}$, as shown in reaction (1).

$$
\mathrm{HSO}_{5}{ }^{-}+\mathrm{SO}_{5}^{2-} \longrightarrow \mathrm{HSO}_{4}{ }^{-}+\mathrm{SO}_{4}{ }^{2-}+{ }^{1} \mathrm{O}_{2}
$$

PMS could also be activated by ketones and benzoquinone to produce ${ }^{1} \mathrm{O}_{2}$ as previously reported ${ }^{51 \text {, }}$ ${ }^{52}$. The carbonaceous materials synthesized in this research could boost the degradation of phenol by activating PMS. So it is likely that more ${ }^{1} \mathrm{O}_{2}$ would be generated during the activation of PMS. TMP was then selected to trap ${ }^{1} \mathrm{O}_{2}$ for EPR, forming the stable TMPN which can be detected by its typical three-line EPR spectrum with equal intensities $\left(a_{N}=16.9 \mathrm{G}, \mathrm{g}=2.0054\right)$. As it is shown in Figure 7 , TMP used here was not oxidized and could not react with N-G due to no peaks detected. Three peaks assigned to TMPN could be seen for PMS only without any catalyst in phenol solution due to the self-decomposition of PMS. However, the intensity is much weak and negligible effect on phenol degradation was produced by PMS only. In addition, the phenol degradation in the system possibly occurred on the interface of catalysts and solution by the surface functionalities. Much more ${ }^{1} \mathrm{O}_{2}$ was then generated in the catalysts/PMS system and N-G showed the greatest intensity of ${ }^{1} \mathrm{O}_{2}$, which could explain the best catalytic performance of $\mathrm{N}-\mathrm{G}$. It could be speculated that ${ }^{1} \mathrm{O}_{2}$ played a dominating 
role in degradation of phenol on N-G. In addition, the higher efficiency of phenol decomposition on $\mathrm{N}-\mathrm{C}-\mathrm{Fe}$ than MOF-C can be attributed to more $\cdot \mathrm{OH}$ radicals, because the intensities of ${ }^{1} \mathrm{O}_{2}$ on $\mathrm{N}-\mathrm{C}$ Fe and MOF-C were almost equal. Moreover, the intensity of ${ }^{1} \mathrm{O}_{2}$ increased rapidly in the first 5 min and then at a slower rate, which was in accordance with the decomposition rate of phenol (Figure 7b), confirming that singlet oxygen dominated the phenol degradation on $\mathrm{N}-\mathrm{G}$. The reaction atmosphere (ambient condition, nitrogen gas and air purging) exerted no influence on phenol degradation as shown in Figure S8, confirming that ${ }^{1} \mathrm{O}_{2}$ was originated from PMS rather than dissolved oxygen in the reaction solution.
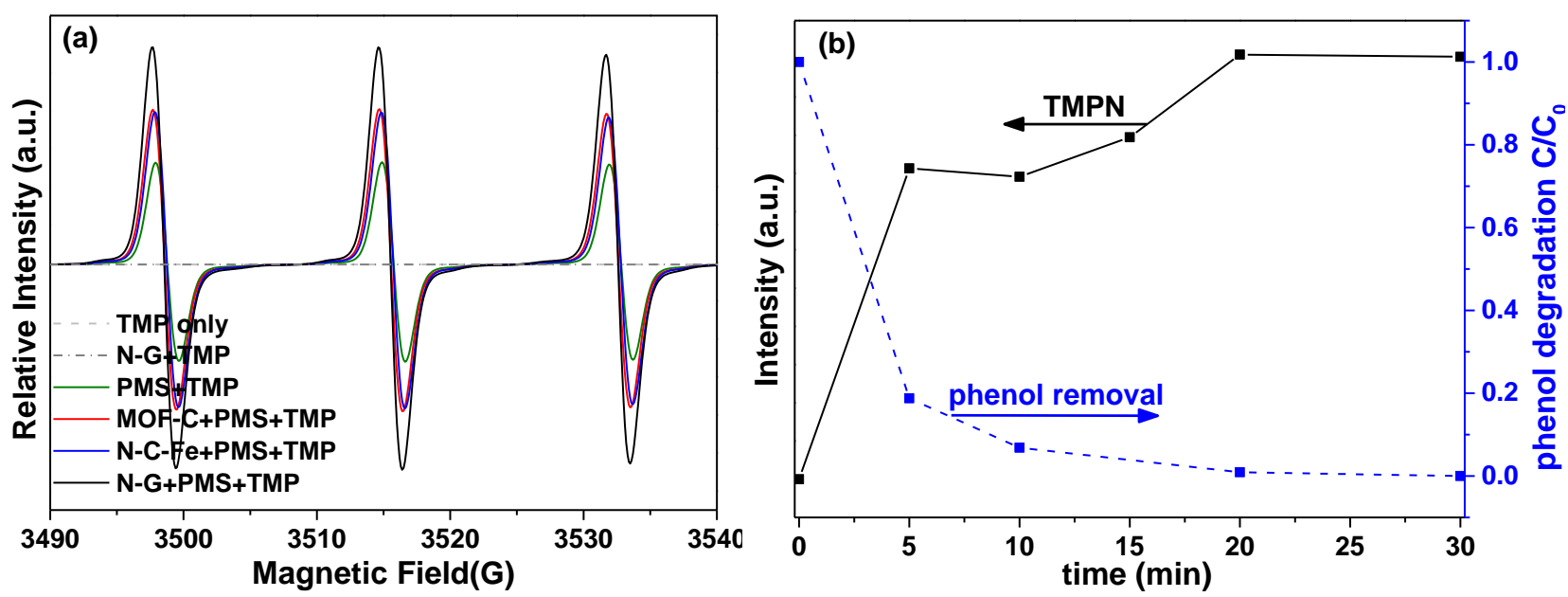

Figure 7. EPR spectra of TMPN on various catalysts (a), variation of singlet oxygen evolution and phenol removal during PMS activation on N-G (b). (catalyst: 100 mg/L, PMS: 3.25 mM, phenol: 50 ppm, temperature: $25^{\circ} \mathrm{C}$, reaction time: $20 \mathrm{~min}$; TMP: $\left.1.16 \mathrm{~g} / \mathrm{L}\right)$.

It was reported that only free radicals were generated during PMS activation by $\mathrm{Co}^{2+} 31,53$. For comparison, TMP was then used as a trapping agent in $\mathrm{Co}_{3} \mathrm{O}_{4} / \mathrm{PMS}$ system (Figure S9). The intensity of ${ }^{1} \mathrm{O}_{2}$ was much lower than PMS only in the initial 5 min and disappeared after 10 min, which was totally different from that on N-G/PMS system.

To further verify the effects of $\bullet \mathrm{OH}$ and $\mathrm{SO}_{4}{ }^{--}$radicals as well as ${ }^{1} \mathrm{O}_{2}$, quenching tests were conducted. Ethanol and tert-butanol were used as the scavengers of $\bullet \mathrm{OH}$ and $\mathrm{SO}_{4}{ }^{--}$radicals. $\mathrm{NaN}_{3}$ was chosen to quench ${ }^{1} \mathrm{O}_{2}$ according to the previous report ${ }^{54}$. Remarkably, ${ }^{1} \mathrm{O}_{2}$ could oxidize phenol 
with a high efficiency while trifle activity towards ethanol and tert-butanol ${ }^{55}$. The rate constants of quenching are shown in Table S1. As shown in Figure 8a, the addition of ethanol and tert-butanol had no influence on phenol degradation, indicating that $\bullet \mathrm{OH}$ and $\mathrm{SO}_{4}{ }^{--}$radicals exhibited negligible effects on phenol oxidation. For comparison, the efficiencies of phenol degradation on MOF-C, C-N and N-C-Fe were inhibited at various degrees by ethanol (Figure S10), suggesting that $\bullet \mathrm{OH}$ and $\mathrm{SO}_{4}{ }^{-}$ radicals contributed to the decomposition of phenol on the above three catalysts.

The addition of $\mathrm{NaN}_{3}$ could hinder the degradation of phenol effectively as shown in Figure $8 \mathrm{~b}$. Although $\mathrm{NaN}_{3}$ could also quench $\bullet \mathrm{OH}$ and $\mathrm{SO}_{4}{ }^{--}$radicals, the scavenging ability of $\mathrm{NaN}_{3}$ at $3 \mathrm{mM}$ $\left(3.6 \times 10^{7}\right.$ and $3 \times 10^{6} \mathrm{~s}^{-1}$, respectively) was weaker than that of ethanol (ethanol $v s . \mathrm{PMS}=1000: 1$, $3.9 \times 10^{12}$ and $2.5 \times 10^{11} \mathrm{~s}^{-1}$, respectively). Ethanol should be more effective in hindering phenol degradation than $\mathrm{NaN}_{3}$ if $\bullet \mathrm{OH}$ or $\mathrm{SO}_{4}{ }^{--}$radicals played the dominant role during the catalytic oxidation. The contrary results indicated that ${ }^{1} \mathrm{O}_{2}$ was the contributor to phenol removal. The presence of $\mathrm{NaN}_{3}(1 \mathrm{mM}$ and $3 \mathrm{mM}$ ) would boost the decomposition of PMS by $\sim 10 \%$ and $24 \%$, respectively (Figure S11a). However, the degradation efficiency of phenol did not decrease when the concentrations of PMS in the reaction solution were 0.7 and $0.9 \mathrm{~g} / \mathrm{L}$ compared with $1 \mathrm{~g} / \mathrm{L}$ (Figure $\mathrm{S} 11 \mathrm{~b})$. As a result, the decrease in degradation efficiency with the addition of $\mathrm{NaN}_{3}$ was attributed to ${ }^{1} \mathrm{O}_{2}$ quenching.
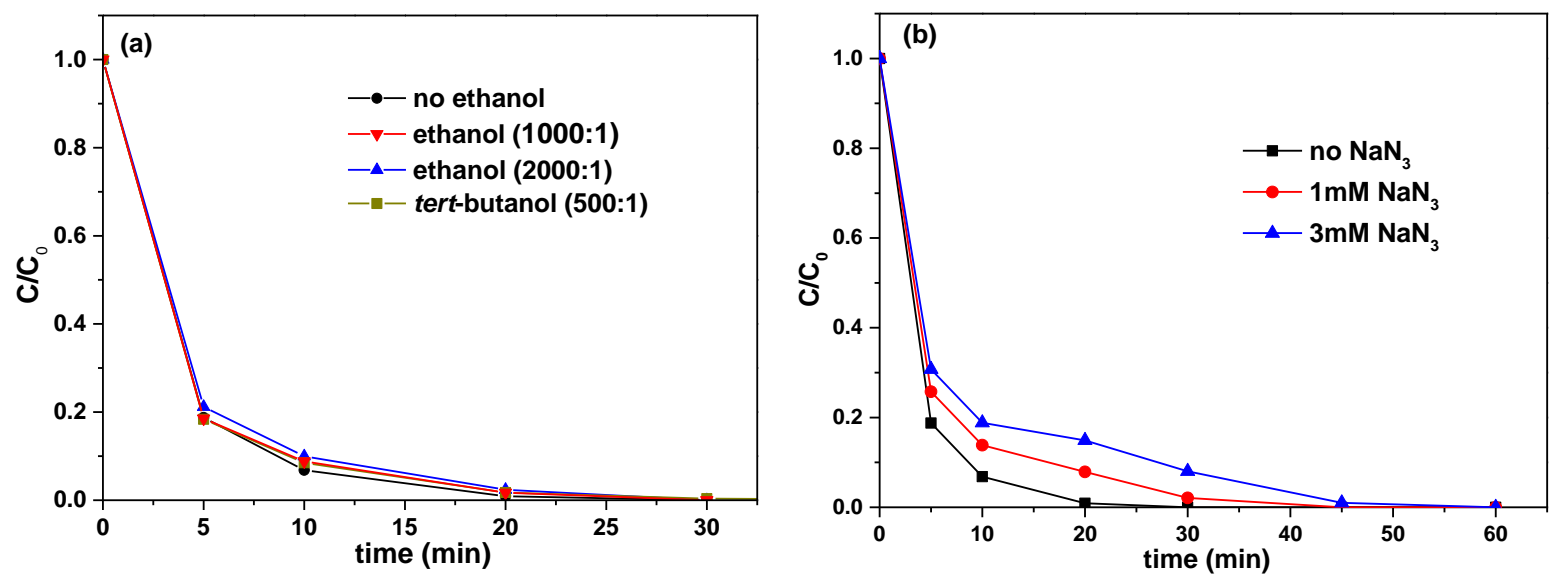

Figure 8. Influence of various quenching agents on phenol degradation. (a) ethanol and tert-butanol as the quenching agents; (b) sodium azide as the quenching agent. Reaction conditions: catalyst: 100 
mg/L, PMS: $3.25 \mathrm{mM}$, phenol: $50 \mathrm{ppm}$, temperature: $25^{\circ} \mathrm{C}$, molar ratio (ethanol vs. PMS) $=1000: 1$ $(2000: 1)$, molar ratio $($ tert-butanol vs. PMS $)=500: 1$.

The influence of $\mathrm{pH}$ on phenol degradation was also investigated (Figure S12), showing that the alkaline condition could enhance the degradation of phenol. For one thing, the phenolate anion exhibits higher reactivity toward ${ }^{1} \mathrm{O}_{2}$ than neutral phenol ${ }^{56-58}$; in addition, alkaline environment facilitated the generation of $\mathrm{SO}_{5}{ }^{2-}$, inducing more singlet oxygen to be produced.

\section{Conclusions}

In this research, N-G was prepared using a mixture of MIL-100(Fe) and DCDA as the precursors in combination with a post-acid treatment. N-G showed excellent phenol degradation by catalytic PMS activation, due to $\mathrm{N}$ doping, fast electron flowing of graphene and high SSA. The mechanism of PMS activation on N-G was investigated by means of both EPR and quenching tests. Singlet oxygen was observed during PMS activation on N-G and was determined to be the primary role in phenol degradation. The N-G/PMS system showed a better efficiency on phenol degradation in alkaline condition. This study opened a facile avenue to synthesize N-doped graphene for environmental remediation and provided a new insight into the catalytic reaction on $\mathrm{N}$-doped graphene.

\section{Acknowledgements}

This project was supported by Australian Research Council (ARC) under Project No.: DP150103026. Characterizations were partially obtained from Curtin University Electron Microscope Facility and Centre for Microscopy Characterization.

\section{Appendix A. Electronic supplementary information}

Additional tables and figures can be found in electronic supplementary information. 


\section{References}

1. A. Dirany, I. Sires, N. Oturan, A. Ozcan and M. A. Oturan, Environ. Sci. Technol., 2012, 46, 4074-4082.

2. W. Tian, H. Zhang, X. Duan, H. Sun, M. O. Tade, H. M. Ang and S. Wang, ACS Appl. Mater. Interfaces, 2016, 8, 7184-7193.

3. H. Sun, S. Liu, G. Zhou, H. M. Ang, M. O. Tade and S. Wang, ACS Appl. Mater. Interfaces, $2012,4,5466-5471$.

4. J. J. Pignatello, E. Oliveros and A. MacKay, Crit. Rev. Environ. Sci. Technol., 2006, 36, 1-84.

5. $\quad$ S. Wang, Dyes Pigm., 2008, 76, 714-720.

6. E. Saputra, S. Muhammad, H. Sun, H. M. Ang, M. O. Tade and S. Wang, Environ. Sci. Technol., 2013, 47, 5882-5887.

7. S. Indrawirawan, H. Q. Sun, X. G. Duan and S. B. Wang, J. Mater. Chem. A, 2015, 3, 34323440.

8. B. Frank, J. Zhang, R. Blume, R. Schlogl and D. S. Su, Angew. Chem., Int. Ed. Engl., 2009, 48, 6913-6917.

9. Z. Yang, Z. Yao, G. F. Li, G. Y. Fang, H. G. Nie, Z. Liu, X. M. Zhou, X. A. Chen and S. M. Huang, ACS Nano, 2012, 6, 205-211.

10. C. Zhang, N. Mahmood, H. Yin, F. Liu and Y. Hou, Adv. Mater., 2013, 25, 4932-4937.

11. H. B. Wang, T. Maiyalagan and X. Wang, ACS Catal., 2012, 2, 781-794.

12. K. Parvez, S. B. Yang, Y. Hernandez, A. Winter, A. Turchanin, X. L. Feng and K. Mu“llen, ACS Nano, 2012, 6, 9541-9550.

13. L. T. Qu, Y. Liu, J. B. Baek and L. M. Dai, ACS Nano, 2010, 4, 1321-1326.

14. N. Li, Z. Y. Wang, K. K. Zhao, Z. J. Shi, Z. N. Gu and S. K. Xu, Carbon, 2010, 48, 255-259.

15. C. Zhang, L. Fu, N. Liu, M. Liu, Y. Wang and Z. Liu, Adv. Mater., 2011, 23, 1020-1024.

16. X. R. Wang, X. L. Li, L. Zhang, Y. K. Yoon, P. K. Weber, H. L. Wang, J. Guo and H. J. Dai, Science, 2009, 324, 768-771. 
17. Q. Li, H. Y. Pan, D. Higgins, R. G. Cao, G. Q. Zhang, H. F. Lv, K. B. Wu , J. Cho and G. Wu, Small, 2015, 11, 1443-1452.

18. Z. H. Rada, H. R. Abid, H. Sun and S. Wang, J. Chem. Eng. Data, 2015, 60, 2152-2161.

19. Z. H. Rada, H. R. Abid, J. Shang, Y. D. He, P. Webley, S. M. Liu, H. Q. Sun and S. B. Wang, Fuel, 2015, 160, 318-327.

20. F. Wang, Z. S. Liu, H. Yang, Y. X. Tan and J. Zhang, Angew. Chem., Int. Ed. Engl., 2011, 50, 450-453.

21. L. H. Ai, C. H. Zhang, L. L. Li and J. Jiang, Appl. Catal., B, 2014, 148-149, 191-200.

22. N. L. Torad, M. Hu, S. Ishihara, H. Sukegawa, A. A. Belik, M. Imura, K. Ariga, Y. Sakka and Y. Yamauchi, Small, 2014, 10, 2096-2107.

23. H. L. Jiang, B. Liu, Y. Q. Lan, K. Kuratani, T. Akita, H. Shioyama, F. Zong and Q. Xu, J. Am. Chem. Soc., 2011, 133, 11854-11857.

24. H. Jin, J. Wang, D. Su, Z. Wei, Z. Pang and Y. Wang, J. Am. Chem. Soc., 2015, 137, 26882694.

25. G. Wu, H. T. Chunga, M. Nelsona, K. Artyushkovab, K. L. Morec, C. M. Johnstona and P. Zelenaya, ECS Trans., 2011, 41, 1709-1717.

26. G. Wu, N. H. Mack, W. Gao, S. G. Ma, R. Q. Zhong, J. T. Han, J. K. Baldwin and P. Zelenay, ACS Nano, 2012, 6, 9764-9776.

27. G. Wu, K. L. More, C. M. Johnston and P. Zelenay, Science, 2011, 332, 443-447.

28. Q. Li, P. Xu, W. Gao, S. Ma, G. Zhang, R. Cao, J. Cho, H. L. Wang and G. Wu, Adv. Mater., 2014, 26, 1378-1386.

29. C. Mao, A. Kong, Y. Wang, X. Bu and P. Feng, Nanoscale, 2015, 7, 10817-10822.

30. Y. Lu, Y. Wang, H. Li, Y. Lin, Z. Jiang, Z. Xie, Q. Kuang and L. Zheng, ACS Appl. Mater. Interfaces, 2015, 7, 13604-13611.

31. X. G. Duan, H. Q. Sun, Y. X. Wang, J. Kang and S. B. Wang, ACS Catal., 2015, 5, 553-559.

32. X. Duan, Z. Ao, L. Zhou, H. Sun, G. Wang and S. Wang, Appl. Catal., B, 2016, 188, 98-105. 
33. Y. K. Seo, J. W. Yoon, J. S. Lee, U. H. Lee, Y. K. Hwang, C. H. Jun, P. Horcajada, C. Serre and J. S. Chang, Microporous Mesoporous Mater., 2012, 157, 137-145.

34. H. Sun, Y. Wang, S. Liu, L. Ge, L. Wang, Z. Zhu and S. Wang, Chem. Commun., 2013, 49, 9914-9916.

35. Y. Xia, G. S. Walker, D. M. Grant and R. Mokaya, J. Am. Chem. Soc., 2009, 131, 1649316499.

36. G. Wu and P. Zelenay, Acc. Chem. Res., 2013, 46, 1878-1889.

37. X. H. Li, S. Kurasch, U. Kaiser and M. Antonietti, Angew. Chem., Int. Ed. Engl., 2012, 51, 9689-9692.

38. M. Sevilla and A. B. Fuertes, Carbon, 2006, 44, 468-474.

39. O. P. Krivoruchko and V. I. Zaikovskii, Mendeleev Commun., 1998, 8, 97-99.

40. G. Wu, M. Nelson, S. Ma, H. Meng, G. Cui and P. K. Shen, Carbon, 2011, 49, 3972-3982.

41. A. Maiti, C. J. Brabec and J. Bernholc, Modern Phys. Lett. B, 1993, 07, 1883-1895.

42. M. Zhao, H. Song, X. Chen and W. Lian, Acta Mater., 2007, 55, 6144-6150.

43. L. F. Lai, J. R. Potts, D. Zhan, L. Wang, C. K. Poh, C. H. Tang, H. Gong, Z. X. Shen, L. Y. Jianyi and R. S. Ruoff, Energy Environ. Sci., 2012, 5, 7936-7942.

44. J. R. Pels, F. Kapteun, J. A. Moulun, Q. Zhu and K. M. Thomas, Carbon, 1995, 33, 16411653.

45. G. Singh, D. S. Sutar, V. Divakar Botcha, P. K. Narayanam, S. S. Talwar, R. S. Srinivasa and S. S. Major, Nanotechnology, 2013, 24, 1-8.

46. X. Duan, Z. Ao, H. Sun, S. Indrawirawan, Y. Wang, J. Kang, F. Liang, Z. H. Zhu and S. Wang, ACS Appl. Mater. Interfaces, 2015, 7, 4169-4178.

47. H. Q. Sun, C. Kwan, A. Suvorova, H. M. Ang, M. O. Tade and S. B. Wang, Appl. Catal., B, 2014, 154, 134-141.

48. Y. X. Wang, H. Q. Sun, X. G. Duan, H. M. Ang, M. O. Tade and S. B. Wang, Appl. Catal., $B, 2015, \mathbf{1 7 2 - 1 7 3 , ~ 7 3 - 8 1 . ~}$ 
49. D. F. Evans; and M. W. Upton, J. Chem. Soc., Dalton Trans., 1985, 6, 1151-1153.

50. D. L. Ball and J. O. Edwards, J. Am. Chem. Soc., 1956, 78, 1125-1129.

51. R. E. Montgomery, J. Am. Chem. Soc., 1974, 96, 7820-7821.

52. Y. Zhou, J. Jiang, Y. Gao, J. Ma, S. Y. Pang, J. Li, X. T. Lu and L. P. Yuan, Environ. Sci. Technol., 2015, 49, 12941-12950.

53. G. P. Anipsitakis, and D. D. Dionysiou, Environ. Sci. Technol., 2003, 37, 4790-4797.

54. H. E. Gsponer, C. M. Previtali and N. A. García, Toxicol. Environ. Chem., 1987, 16, 23-37.

55. M. A. J. Rodgers, J. Am. Chem. Soc., 1983, 105, 6201-6205.

56. H. Kim, W. Kim, Y. Mackeyev, G. S. Lee, H. J. Kim, T. Tachikawa, S. Hong, S. Lee, J. Kim, L. J. Wilson, T. Majima, P. J. Alvarez, W. Choi and J. Lee, Environ. Sci. Technol., 2012, 46, 9606-9613.

57. P. G. Tratnyek, and J. Hoigne., Environ. Sci. Technol., 1991, 25, 1596-1604.

58. J. Lee, S. Hong, Y. Mackeyev, C. Lee, E. Chung, L. J. Wilson, J. H. Kim and P. J. Alvarez, Environ. Sci. Technol., 2011, 45, 10598-10604. 